\title{
PSICOLOGIA E EDUCAÇÃO: NOVAS PERSPECTIVAS PARA A EDUCAÇÃO BRASILEIRA
}

\author{
PSICOLOGÍA Y EDUCACIÓN: NUEVAS PERSPECTIVAS PARA LA EDUCACIÓN \\ BRASILEÑA
}

\author{
PSYCHOLOGY AND EDUCATION: NEW PERSPECTIVES FOR BRAZILIAN \\ EDUCATION
}

Ivy Elida GUIMARÃES SALES ${ }^{1}$

RESUMO: O presente artigo tem como objetivo pensar a psicologia e a educação, refletindo ainda sobre a atual Lei $\mathrm{n}^{\circ} 13.935$, que legitima a atuação do psicólogo na escola a partir da equipe de multiprofissionais. Os argumentos foram construídos sobre os seguintes questionamentos: qual a relação da psicologia na educação? Como será a atuação do psicólogo na escola junto a equipe de multiprofissionais? O estudo parte de uma revisão bibliográfica além de fomentar a reflexão sobre a nova lei.

PALAVRAS-CHAVE: Psicologia. Educação. Aprendizagem.

RESUMEN: Este artículo tiene como objetivo pensar en psicología y educación, reflexionando también sobre la actual Ley $N^{\circ} 13.935$, que legitima el desempeño del psicólogo en la escuela del equipo multiprofesional. Los argumentos se basaron en las siguientes preguntas: ¿cuál es la relación de la psicología en la educación? ¿Cómo actuará el psicólogo en la escuela con el equipo multiprofesional? El estudio parte de una revisión bibliográfica y fomenta la reflexión sobre la nueva ley.

PALABRAS CLAVE: Psicología. Educación. Aprendizaje.

ABSTRACT: This article aims to think about psychology and education, also reflecting on the current Law No. 13,935, which legitimizes the performance of the psychologist in school from the multiprofessional team. The arguments were built on the following questions: what is the relationship of psychology in education? How will the psychologist act at school with the multiprofessional team? The study starts from a bibliographic review and encourages reflection on the new law.

KEYWORDS: Psychology. Education. Learning.

\footnotetext{
${ }^{1}$ Universidade Federal de Roraima (UFRR), Boa Vista - RR - Brasil. Mestre em Antropologia Social (UFRR).
} Pedagoga (FAPAN). ORCID: https://orcid.org/0000-0002-3153-7930. E-mail: ivyelida@gmail.com 


\section{Introdução}

O presente artigo tem como objetivo pensar a psicologia e educação e a atual Lei ${ }^{0}$ 13.935, que legitima a atuação do psicólogo nas escolas. Os argumentos foram construídos sobre os seguintes questionamentos: qual o papel da psicologia na educação? Como será a atuação do psicólogo na escola? O estudo foi realizado a partir da análise bibliográfica de artigos, livros, dissertações e teses que trazem a temática da relação Educação e Psicologia.

Para compreender a importância dos estudos da psicologia na educação, tanto na formação docente como na compreensão do indivíduo, torna-se necessário aprender sobre o que é a psicologia e assim conhecer a maneira como essa ciência é convidada para a educação. Para tanto, observaremos uma breve história da psicologia.

De acordo com Schutz e Schutz (2002, p. 17), o estudo da psiqué está presente entre os pensadores gregos desde o século V a.c., período em que alguns filósofos, dentre esses Platão e Aristóteles, já se ocupavam de estudos sobre "a memória, a aprendizagem, a motivação, a percepção, a atividade onírica e o comportamento anormal". Esses estudos geravam questionamentos que não se dissiparam e nem encontraram respostas e ainda hoje permeiam as investigações psicológicas.

Nessa vertente, Silva (2018) explica que o surgimento da psicologia como ciência remonta ao final do século XIX e início do século XX, por meio dos estudos realizados tanto pelo método da observação como da experimentação. No ano de 1879, na cidade de Leipzig, Alemanha, um fisiologista chamado Wilhelm Wundt construiu o primeiro laboratório de psicologia em todo o mundo. Wundt ficou conhecido como o "pai" da psicologia moderna, ou seja, o responsável pela psicologia como temos hoje, em que o objeto de pesquisa transcendeu apenas os questionamentos filosóficos e passa a ser fruto de experimentação. Com esse novo cenário a Psicologia passa a contar diversas pesquisas e logo surgiram as primeiras revistas cientificas com as publicações dos relatos das experiencias; em 1881 Wundt funda a Philosophiche Studien, essa foi considerada a primeira revista de psicologia

Mesmo a Psicologia tendo surgido na Alemanha, foi nos Estados Unidos que ela obteve o desenvolvimento como a ciência moderna que temos hoje. A construção da psicologia do século XX, tem como ponto de ruptura o distanciamento das questões filosóficas e a associação com a medicina, através do Estruturalismo, Funcionalismo e Associacionismo como explicam Bock et al. (2001, p. 43).

Com isso, Silva (2018, p. 63), afirma que "Libertando-se da filosofia e fisiologia, a psicologia científica passou a buscar novos padrões de conhecimento"; a nova ciência buscou 
delimitar o campo de estudos, definiu o objeto e formulou métodos de estudos e construiu teorias. Desse modo, a psicologia é compreendida mais no plural do que no singular, desse processo de autonomia são elaboradas cinco escolas. E, para cada linha de interesse pensada uma psicologia, as correntes de pensamentos chamadas de abordagem possuem um método de análise e uma concepção sobre a mente e o indivíduo.

Desse modo, é necessário compreender que todas as abordagens contribuíram para pensar o processo de aprendizagem e desenvolvimento do ser humano. Os estruturalistas na procura pelo entendimento das estruturas responsáveis pelas ações humanas; pensamento, sentimento e percepção. Representada por Edward Titchener (1867 a 1927) e Wilhelm Wundt (1832 a 1920). O associacionismo procurou explicar o processo de aprendizagem a partir da associação das ideias; partido das menos elaboradas para as mais impenetráveis, representado por Edward L. Thorndike, que é responsável por formular uma primeira teoria de aprendizagem na Psicologia (BOCK et al., 2001).

Pensando agora o funcionalismo, essa abordagem procurava investigar os processos mentais, observando a função dessa junto ao organismo. Uma corrente de pensamento desenvolvida no Estados Unidos e que tem William James (1842-1910) como representante na psicologia. O funcionalismo estava presente nos estudos de James que defendia a evolução biológica como um mecanismo que proporcionou ao ser humano pensar e refletir sobre o seu meio e assim se adaptar ao ambiente.

Frente a essas teorias, no século XX novas investigações chegam a questões epistemológicas e, com isso, surge o Behaviorismo e Gestalt. O Behaviorismo pode ser compreendido como uma análise experimental do comportamento, tem como representante John B. Watson, e pode ser compreendido a partir da observação que determinados estímulos produzem determinadas respostas, isso é explicado partindo da ideia de que os organismos se adaptam ao ambiente tanto através de características genéticas como pelo hábito.

A Gestalt, elaborada no final do século XIX, por meio do filosofo e psicólogo, Chrinstiam von Ehrenfels (1859-1932) que desenvolvia pesquisas sobre as sensações do tempo, forma e espaço, mostrando que para um entendimento concreto do todo não basta apenas conhecer as partes. A psicanálise elaborada pelo psiquiatra Freud, tem como base de investigação o inconsciente. Apesar da psicanálise ser hoje uma formação a parte da psicologia, a contribuição de Freud é imensurável para os estudos da ciência.

Portanto, a história da psicologia e a delimitação do objeto dentro de suas "escolas", buscando compreender sobre o comportamento, a consciência e a vida psíquica, mostrou 
importantes estudos que contribuíram e contribuem para a compreensão do processo de ensino e aprendizagem ao longo do desenvolvimento do indivíduo.

Ao observar essas teorias é possível refletir sobre as dimensões que estão envoltas nelas, pois mesmo que os impulsos e investimentos das pesquisas tenham partido dos grupos dominantes (VIANA, 2016), obviamente, com a expansão dos estudos e da ciência as descobertas, métodos e teorias podem ser aplicadas nos mais diversos estratos sociais. E, ainda que "Várias teorias psicológicas, direta ou indiretamente fundamentadas no liberalismo individualizante, têm levado os trabalhos por um caminho que responsabiliza o indivíduo pelos seus desajustamentos." (VIANA, 2016, p. 55). O entrelaçamento da psicologia com outras ciências, outras perspectivas (antropologia, sociologia, educação), proporcionou reverberar essa visão e desenvolver estudos que apresentam uma desconstrução da visão liberalista, sabendo que o indivíduo é também um sujeito resultados das interações sociais, uma coexistência social e biológica, e esse biológico é diretamente influenciado pelo meio ambiente, ou seja, pelo social, logo, o indivíduo e seus desajustes não podem ser vistos de um ponto de vista único, mas sim de uma perspectiva que envolve as várias dimensões que corroboram com a construção de um indivíduo saudável ou não; situação econômica, cultural, social e biológica.

\section{A psicologia na educação}

Cada indivíduo e suas expressões podem ser entendidos, de um ponto de vista social, como a soma de diversas experiências, o nosso comportamento verte sobre tudo aquilo que vivenciamos e aprendemos de diversas formas, de maneira intrínseca à nossas interações. Davis (1994) explica que é no convívio social que se criam as condições para o aparecimento da consciência. Refletir sobre as próprias condições e a existência compreende um dos aspectos que fazem o humano, no entanto, esse reflexão que é entendida como consciência só existe a partir da comunicação, ou seja: temos consciência de nós mesmos e refletimos isso a partir da existência do outro, logo, o ser humano se forma a partir do social, do convívio com outros de mesma espécie e da interação. Por meio da cultura o indivíduo torna-se sujeito de sua existência e modifica seu espaço, na medida que também se modifica.

Seguindo essa linha de pensamento, podemos compreender que existem mecanismos sociais que estabelecem formas estruturadas de pensar e agir, mecanismos de controle que produzem uma regularização dos comportamentos. Dentre esses mecanismos encontram-se as instituições sociais que promovem a inserção do indivíduo no mundo, por meio delas ele aprende as características culturais: linguagem, costumes, tradições, trabalho e produção. A 
educação escolar é uma instituição social presente em diversas culturas, que atua como forma de socialização e é responsável por abrir caminho para a aprendizagem cientifica. Além disso, a educação tanto a informal como a escolar estão vinculadas as atividades práticas, como explica Paulo Freire (2003, p. 40): “A educação é sempre uma certa teoria do conhecimento posta em prática [...]". Desse modo a prática é o resultado do processo de aprendizagem, portanto só existe a educação porque existe o ensinar e o aprender.

A educação na sua forma mais ampla é compreendida como um processo social, mas quando observamos a forma como o indivíduo aprende as práticas sociais, entramos em um espaço de estudo próprio da psicologia, o indivíduo. O processo de aprendizagem ocorre na apropriação dos conhecimentos existentes em uma sociedade, através de outros indivíduos mais experientes. Por meio de redes de relações as interações são as ações que partilham os conhecimentos, e nesse processo a escola tem o papel de proporcionar a estruturação, por meio do professor e dessas interações (DAVIS, 1994, p. 22). Nesse viés, pensar a psicologia na educação nos remete a ver que é necessário compreender sobre as bases do desenvolvimento e da aprendizagem dos indivíduos, em que pese assimilar o entendimento que o processo de aprendizagem tem início. No entanto, é importante saber que a aprendizagem não é um processo único;

Existem diversos tipos de aprendizagem, consubstanciadas nas mais variadas atividades da vida humana. Algumas aprendizagens se dão desde os primeiros anos de vida e estão vinculadas ao cotidiano da pessoa, como: sentar-se, andar, falar, identificar e pegar objetos, comer sozinha etc. Outras acontecem de forma sistemática em instituições próprias, como a escola (NUNES; SILVEIRA, 2015, p. 10).

Como explica a psicóloga, a aprendizagem acontece em todos os ambientes, assim que o ser humano tem as primeiras interações, desde o útero a criança já recebe estímulos, e após seu nascimento ela vai observando e aprendendo de acordo com os incentivos que vai recebendo, por isso é tão importante pensar os ambientes e as relações às quais expor as crianças, tendo em vista os resultados a partir dos influxos colocados durante a educação escolar, pois se compreende o ensino escolar como uma forma de promover a aprendizagem, proporciona estímulos para o desenvolvimento. Sobre o processo de aprendizagem Vygotsky (2008) explica que,

O nível do pensamento da criança não deve ser avaliado por aquilo que ela aprendeu através da instrução, mas sim pelo modo como ela pensa sobre assuntos a respeito dos quais nada the foi ensinado. Aqui, a separação - na verdade, a oposição - entre o aprendizado e o desenvolvimento é levada ao seu extremo (VYGOTSKY, 2008, p. 118-119). 
Nessa linha de pensamento podemos observar que a psicologia está vinculada à educação, em seus aspectos intrínsecos ao indivíduo, no processo de aprendizagem e no processo de desenvolvimento tendo em vista que esses estão vinculados ao ser biológico e social. Nesse viés, a psicologia junto da educação é uma colaboração fértil no campo da pesquisa, gerando estudos sobre o processo de ensino e aprendizagem, no que compreende tanto o desenvolvimento de estratégias de ensino como de formação e capacitação de professores educadores. Atualmente os cursos de formação de professores possuem no currículo a obrigatoriedade do ensino sobre o processo de aprendizagem e desenvolvimento e em muitos casos existe a disciplina denominada de Psicologia da Educação, como observaram Machado e Costa (2016). Essa inserção, pela teoria da psicologia, é também a busca pelo fomento a compreensão de que os indivíduos possuem especificidades e que sua subjetividade deve ser respeitada e cultivada, o professor com seu papel indispensável às sociedades atua na formação dos indivíduos mostrando caminhos para a construção do pensamento e autonomia.

Assim é o papel da Psicologia da Educação, buscar construir investigações que permitam a aprendizagem de todos, dentro de suas necessidades próprias e de maneira a respeitar as experiencias do indivíduo. Algo a se pensar (GUZZO et al., 2010), a vinculação da psicologia apenas às ocasiões que envolvam dificuldades de aprendizagem, a psicologia no contexto da educação tem como foco as mais diversas expectativas, dentre elas os bons resultados de aprendizagem e a superação de obstáculos, sejam de interação ou aprendizagem.

A Psicologia junto da Educação estabelece um elo entre estudos e práticas, análise e compreensão, isso porque pensar a educação envolve aspectos mais gerais como a observação histórica, social, cultural, econômica e geográfica dos envolvidos. A Psicologia da Educação não desenvolve esses pontos como mecanismos de ensino, mas isso fica subentendido, pois todos esses aspectos influenciam diretamente o desenvolvimento e aprendizagem dos indivíduos.

Um educador em sua atuação não deve pensar a prática como uma ação uniforme, cada espaço possui suas necessidades, logo, quando ele percebe a psicologia como aliada da educação, o sujeito pode corroborar com uma prática que permita desenvolver e fortalecer positivamente as características individuais, pensando em mecanismo para auxiliar a superação de possíveis dificuldades e pensando a articulação para estimular as possíveis facilidades. Desse modo a psicologia como aliada da educação se concentra no entendimento que dificuldades de aprendizagem e facilidades devem ser sempre vistas em um conjunto, espaço físico, indivíduos e sociedade. Procurando nas interações soluções e aprimoramentos. 


\section{Novos desafios para a psicologia e a educação}

Em 12 de dezembro de 2019 foi promulgada a lei Lei $\mathrm{n}^{\mathrm{o}} 13.935$, de 11 de dezembro de 2019, que estabelece a obrigatoriedade dos serviços de psicologia e serviço social "para atender às necessidades e prioridades definidas pelas políticas de educação, [...]”

Art. $1^{\circ}$ As redes públicas de educação básica contarão com serviços de psicologia e de serviço social para atender às necessidades e prioridades definidas pelas políticas de educação, por meio de equipes multiprofissionais.

$\S 1^{\circ}$ As equipes multiprofissionais deverão desenvolver ações para a melhoria da qualidade do processo de ensino-aprendizagem, com a participação da comunidade escolar, atuando na mediação das relações sociais e institucionais.

$\S 2^{\circ} \mathrm{O}$ trabalho da equipe multiprofissional deverá considerar o projeto político-pedagógico das redes públicas de educação básica e dos seus estabelecimentos de ensino (BRASIL, 2019, p. 07).

A psicologia sempre caminhou junto à educação, seja na busca por compreender o processo de desenvolvimento do indivíduo ou entender o processo de aprendizagem. Viana (2016) expõe que no processo de formação da psicologia científica como conhecemos hoje, a educação esteve como epicentro das pesquisas psicológicas. Porém,

A partir da década de 1980 e no decorrer da década de 1990, verificamos que se passa a questionar a universalidade de teorias psicológicas e das técnicas de avaliação, afirmando uma relação mais próxima entre a psicologia e a sociedade, onde se passou inclusive a defender a interdisciplinaridade como um recurso fundamental na compreensão do comportamento humano (VIANA, 2016, p. 56).

Nesse novo cenário brasileiro, em que o estreitamento da educação e psicologia está a ocorrer, mais questionamentos serão levantados sobre a atuação do psicólogo na escola e seu papel na formação educacional, além disso cabe saber como se desenrolará a atuação junto aos educadores, e a todo o corpo docente, que possivelmente levantará questionamentos quanto ao limite de atuação do profissional, tendo em vista que a atuação do professor poderá ser construída a partir de uma correlação com os demais profissionais, pois a atuação conjunta dos multiprofissionais discorrerá para a busca em alcançar em uma construção conjunta o melhor desenvolvimentos dos educandos.

Nesse pensamento, questiona-se a necessidade de implementação e capacitação para que a equipe multiprofissional desenvolva seu potencial sem causar estranhamento às equipes pedagógicas, tendo em vista que mesmo a psicologia estando presente tanto na formação docente como atuando junto ao processo de aprendizagem, a inserção do profissional psicólogo 
junto ao ambiente escolar, portanto junto às equipes pedagógicas, poderá ser uma transformação positiva tanto para o processo de ensino, assim como vem sendo feito, quanto para a psicologia da educação e escolar. Compreendendo a diversidade do ensino no Brasil, as inúmeras dificuldades que a educação vem enfrentando; violência em sala de aula, falta de infraestrutura, de investimentos. Todas essas questões irão fazer parte das necessidades de atuação do psicólogo e, mais que trabalhar com o indivíduo, o profissional terá que observar e construir a ação com os grupos.

Portanto, um novo cenário será iniciado na educação brasileira, para a psicologia e os profissionais de educação que sempre estiveram próximos nas teorias e objeto de pesquisa, agora construirão novas experiências de interação.

\section{Considerações finais}

As principais observações sobre a Psicologia e a Educação como colaboradoras não tratou-se de algo direcionado, mas de como a psicologia, ao trabalhar seu objeto de estudo e desenvolver suas investigações cientificas, produziu uma estruturação de conhecimentos que contribuem para a formação docente, entende-se que mesmo a psicologia não tendo criado uma base de pesquisa escolar essa está fortemente vinculada ao que conhece-se atualmente sobre o processo de ensino e aprendizagem.

Ao observar a educação e o processo escolar é possível perceber que o todo é um fluxo contínuo e que um estímulo em qualquer ponto pode gerar as mais diversas modificações. Portanto, caso a formação de professores ganhe mais incentivo e com isso mais comprometimento, certamente, em pouco tempo, isso será sentido no ensino escolar. A educação é uma instituição social, é nela que a maioria dos seres humanos passam grande parte do seu tempo, a educação no Brasil é um direito de todos, dever do estado e da família, portanto, é obrigatória a frequência das crianças à escola.

Assim, vê-se dois movimentos diferentes, um é a contribuição da psicologia para a formação docente e sua capacidade de trabalhar com a subjetividade dos educandos, o outro considera a presença do psicólogo nos ambientes educacionais, não como um auxilio clinico, mas como um pilar que sustenta as necessidades mais individuais de aprendizagem que não podem ser acionadas pelo professor, tanto por não possuir formação como por não dispor de mecanismos adequados.

Concluindo, pode-se observar que a psicologia está presente na formação docente por meios da apresentação das teorias que proporcionam um entendimento sobre o processo de 
aprendizagem e desenvolvimento do indivíduo, e a educação está presente na psicologia, quando se pensa o desenvolvimento científico que, ao longo da história, foi sendo construído com base nos interesses da sociedade, porém olhando de uma maneira micro, vê-se que o a educação no Brasil, a partir da aprovação da Lei $\mathrm{n}^{\mathrm{o}} 13.935$, iniciará um novo processo educacional que prevê uma nova inserção da psicologia e assistência social no processo de educação.

Novos desafios, novas perspectivas poderão ser construídas e, a psicologia tanto para a atuação do psicólogo como para a psicologia da educação, ao se pensar os questionamentos e investigações científicas que irão surgir dessa aproximação da psicologia com a educação, se tornará a presença mais nítida do psicólogo na educação e no ambiente escolar, e, principalmente, esse não na figura de um investigador clinico mas sim um observador social que terá sua ação mais ampliada e multidimensionada.

\section{REFERÊNCIAS}

ABIB, J. A. D. Epistemologia pluralizada e história da psicologia. Sci. stud., São Paulo, v. 7, n. 2, p. $195-208,2009$

BOCK, A. M. B. et al. Psicologias uma introdução ao estudo de psicologia. 13. ed. São Paulo: Editora Saraiva, 2001.

BRASIL, Lei n. 13.935, de 11 de dezembro de 2019. Dispõe sobre a prestação de serviços de psicologia e de serviço social nas redes públicas de educação básica. Diário Oficial da União, Brasília, Edição 240, Seção 1, p. 7, 12 dez. 2019.

CUNHA, M. V. da. Psicologia da educação. 4. ed. Rio de Janeiro: Lamparina, 2008. Disponível em: https://colapsi.files.wordpress.com/2018/03/1-piaget-inteligc3aanciaeditado.pdf. Acesso em: 10 dez. 2019.

DAVIS, C.; OLIVEIRA, Z. de M. R. de. Psicologia na educação. São Paulo: Cortez, 1994.

FREIRE, P. Desafios da educação de adultos ante a nova reestruturação tecnológica. In:

Pedagogia da indignação: cartas pedagógicas e outros escritos. São Paulo: UNESP, 2003. Arquivo PDF. Disponível em:

http://comunidades.mda.gov.br/portal/saf/arquivos/view/ater/livros/Pedagogia_da_Indigna\%C 3\%A7\% C3\%A3o.pdf. Acesso em: 03 nov. 2019.

GOMES, W. B. História da Psicologia para curso de graduação. In: FREITAS, R. H. de (Org.). História da psicologia: pesquisa, formação, ensino. Rio de Janeiro: Biblioteca Virtual de Ciências Humanas do Centro Edelstein de Pesquisas Sociais, 2008. Disponível em: http://books.scielo.org/id/c2248/pdf/freitas-9788599662830.pdf. Acesso em: 03 nov. 2019. 
GUZZO, R. S. L. et al. Psicologia e Educação no Brasil: uma visão da história e possibilidades nessa relação. Psic.: Teor. e Pesq., Brasília, v. 26, n. spe., p. 131-141, 2010. Disponível em: http://www.scielo.br/scielo.php?script=sci_arttext\&pid=S0102$37722010000500012 \& \operatorname{lng}=$ en\&nrm=iso. Acesso em: 10 jan. 2020. DOI: http://dx.doi.org/10.1590/S0102-37722010000500012

LOPES, I. G. (Org.). História da educação no Brasil: desafios e perspectivas. Curitiba, PR: Atena Editora, 2016.

MACHADO, C. A.; COSTA, L. B. Ensino de Psicologia na formação de professores: uma aproximação com diálogos possíveis. Pro-Posições, v. 27, n. 2, p. 221-234, 2016.

NUNES, A. I. B. L.; SILVEIRA, R. N. Psicologia da aprendizagem. 3. ed. rev. Fortaleza: EdUECE, 2015.

OLIVEIRA, G. G. Neurociência e os processos educativos: um saber necessário na formação de professores. 2011. 146 f. Dissertação (Mestre em Educação) - Universidade de Uberaba, Uberaba, MG, 2011.

PRADO, M. S. M. Psicologia da educação. Cruz das Almas, BA: SEAD-UFRB, 42 p, 2017.

SCHULTZ, D. P.; SCHULTZ, S. E. História da psicologia moderna. São Paulo: Cultrix, 2002.

SILVA, E. C. F. História da epistemologia psicológica: o desenvolvimento e o papel dos cientistas no campo da psicologia. São Paulo: Figueira Digital/Agbook, 2018.

SOUZA, E. R. de. A escola como instituição social: revisitando a função social da escola. Londrina, 2013. 80 f. Dissertação (Mestrado em Educação) - Universidade Estadual de Londrina, Londrina, 2013.

VIANA, M. N. Interfaces entre a psicologia e a educação: reflexões sobre a atuação em psicologia escolar. In: Psicologia escolar: que fazer é esse? Brasília: CFP, 2016.

VYGOTSKY, L. S. Pensamento e Linguagem. Trad. Jefferson Luiz Camargo; Revisão técnica: José Cipolla Nelo. 4. ed. São Paulo: Martins Fontes, 2008.

\section{Como referenciar este artigo}

GUIMARÃES SALES, I. E. Psicologia e educação: novas perspectivas para a educação brasileira. Doxa: Rev. Bras. Psico. e Educ., Araraquara, v. 22, n. 1, p. 21-30, jan./jun., 2020. e-ISSN: 2594-8385. DOI: https://doi.org/10.30715/doxa.v22i1.13227

Submetido em: $16 / 01 / 2020$

Revisões requeridas em: 31/03/2020

Aceito em: 25/04/2020

Publicado em: 01/06/2020 